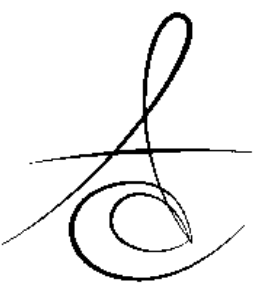

\title{
6-7 YAŞ OKUL ÇOCUKLARININ AĞIZ SAĞLIĞI EĞİTíMİNDE Dİş HEKİMLERİ İLE OKUL ÖĞRETMENLERİNİN ETKİNLİĞİNİN KARŞILAŞTIRILMASI
}

\author{
COMPARISON OF THE EFFECTIVENESS OF SCHOOL TEACHERS AND \\ DENTISTS IN ORAL HEALTH EDUCATION FOR 6-7 YEAR OLD CHILDREN
}

\author{
Dr. Öğr. Üyesi Berna KUTER*
}

\author{
Dr. Öğr. Üyesi Burcu KANMAZ**
}

\begin{abstract}
Makale Kodu/Article code: 3805
Makale Gönderilme tarihi: 25.07.2018
\end{abstract}

Kabul Tarihi: 05.12.2018

\section{öz}

Amaç: Çalışmanın amacı, yaşları itibariyle ailelerinden etkilenen 6-7 yaş çocuklarının ağız sağlığı eğitiminde diş hekimleri ile okul öğretmenlerinin etkinliklerinin karşılaştııılmasıdır.

Gereç ve Yöntem: Yapılan çalışmada ilkokula giden 160 çocuk iki gruba ayrımışıtır. A grubuna öğretmen, B grubuna diş hekimi ağız sağlı̆ı eğitimi vermiştir. Çocukların ağız sağlığı ağız hijyeni, plak indeks, def-t indeks (çürük çekilmiş dolgulu süt dişi sayısı), def-s indeks (çürük çekilmiş dolgulu süt dişi yüzeyi), DMF-T indeks (çürük çekilmiş dolgulu daimi diş sayısı) ve DMF-S indeks (çürük çekilmiş dolgulu daimi diş yüzeyi) değerleri ölçülerek eğitim öncesi ve sonrası değerlendirilmiştir. Öğretmen ile diş hekiminin verdiği eğitimin farkı değerlendirilmiştir.

Bulgular: Eğitim sonrası her iki grubun ağız hijyeni düzelmiş fakat plak indeks değeri azalmamıştır. Eğitim öncesi ve sonrası def-t, def-s, DMF-T and DMF-S indeks değerleri benzer bulunmuştur. $\mathrm{Bu}$ indeks değerlerine göre öğretmen ve diş hekiminin verdiği eğitimin ağız sağlığına etkisi benzer bulunmuştur.

Sonuç: Okul öğretmenleri ile diş hekimlerinin verdiği ağız sağı̆̆ı eğitiminin benzer olduğu ve öğretmenlerin de ağız sağlı̆ı eğitimi için uygun olduğu sonucuna varılmıştır. Öğretmen ve ailenin birlikte yer aldığı, belirli aralıklarla takip edilen başka çalışmaların yapılmasına ihtiyaç olduğu düşünülmektedir.

Anahtar Kelimeler: Ağız sağlığı eğitimi, Ağız hijyeni, Okul sağlık eğitim programı

\section{ABSTRACT}

Aim: The purpose of the study is to comparison of the effectiveness of teachers and dentists in oral health education for 6-7 year old children affected by their families.

Material and Methods: The 160 children who attended to primary school were divided into two groups, in this study. The teacher gave oral dental health education to group $A$, the dentist gave to group B. Oral hygiene, plaque index, def-t index (decayed extracted filled primary tooth), def-s index (decayed extracted filled primary tooth surface), DMF-T index (decayed extracted filled permanent tooth) and DMF-S index (decayed extracted filled permanent tooth surface) were evaluted before and after oral health education. The differences between the educations given by the teacher and the dentists were evaluated.

Results: After education oral hygiene improved in both groups, plaque index value did not decrease. The values of def-t, def-s, DMF-T and DMF-S index were similar before and after oral health education. There was no difference between the oral health education by the school teacher and the dentist considering these index values.

Conclusions: It was concluded that oral health education was provided by school teachers and dentist was similar and that the school teachers were suitable for oral health education. It is believed that there is a need for further work to be carried out at regular intervals, where the teacher and family take part.

Key Words: Oral health education, Oral hygiene, School health education programme

\footnotetext{
"İzmir Demokrasi Üniversitesi, Pedodonti A.D. İzmir.

**̇zmir Demokrasi Üniversitesi, Periodontoloji A.D. İzmir.
}

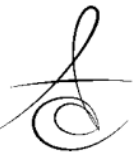




\section{GİRİŞ}

Diş hekimliğindeki koruyucu uygulamalar ağız diş sağlığına ilişkin ortaya çıkabilecek sorunların çözülmesinde en etkili yöntem olarak bildirilmiştir. ${ }^{1} \mathrm{Bu}$ uygulamalar tedavi edici çalsşmalara göre ucuz ve basit olmaları nedeniyle tercih edilmektedir. ${ }^{2}$ Koruyucu diş hekimliği çalışmalarının özellikle toplumun geleceği olan çocuklar üzerinde yoğunlaştırıması, ileride sağlıkı nesillere sahip olunmasını sağlayacaktır. ${ }^{3}$ Diş hastalıklarının beslenme, hayat kalitesi, büyüme ve gelişme üzerindeki olumsuz etkileri nedeniyle çocuklarda ağız diş sağlığı eğitimi verilmesi önemlidir. ${ }^{4}$ Çocuklarla sürekli yakın ilişki içinde olan, eğitim psikolojisi ve bireye uygun öğrenme şekli konusunda tecrübeli okul öğretmenlerinin, sağlık eğitiminin verilmesi ve yaygınlaştırımasında önemli bir pozisyonu bulunmaktadır. ${ }^{5}$ Sadece çocukların değil aynı zamanda ailelerinin ve okul çalışanlarının da ağız diş sağlığı eğitimine ulaşabileceği ve faydalanabileceği bir ortam olması nedeniyle okul ortamı oldukça etkilidir. ${ }^{6}$ Hastalıkların kontrol edilebilir düzeyde olduğu çocuk yaş grubunda koruyucu uygulamalar yapılması ağız sağlığının iyileştirilmesinde çok önemli bir yere sahiptir. ${ }^{7}$ Öğretmen, çocuk ve aile eğitiminin birlikte yapılmasının sadece çocuk eğitimine göre daha başarılı ve anlamlı olduğu bildirilmişdir. ${ }^{7}$ Ağız diş sağlığı ülkenin sağlık programlarının en önemli parçası olup okul çağındaki çocuklara yönelik koruyucu ve tedavi edici programların artırıması gerekmektedir. ${ }^{8}$ Biesbrock, Tai ve ark., çocuklarda ağız hijyeni bilgi ve davranış kazanımlarının geliştirilmesinde en etkili yöntemin okul bazlı ağız sağı̆ğı eğitimi olduğunu bildirmişlerdir. ${ }^{9-10}$ Morishita ve ark., da sağlık eğitimi verilmesinde en uygun çevresel koşulları sağlayan okul ortamının, çocukların etkili ve kalıcı öğrenmesine imkan verdiğini belirtmişlerdir. ${ }^{11}$ Tezel ve ark., Erzurum ilinde ilkokul öğrencilerine yaptıkları çalışmada çocukların ağız diş sağıı̆ı ile ilgili ilk bilgilerinin \% 45.8'ni okuldan, \% 3.2'sini diş hekimlerinden öğrendikleri bildirilmişdir. ${ }^{12}$ Angelopoulou ve ark., ${ }^{13}$ öğretmenlerin verdiği eğitimlerin diş hekimlerinin geleneksel ağız sağlığı eğitimlerine kıyasla daha etkili olduğunu savunmuşlardır. Çocuklarda ağız diş sağlığı eğitiminde öğretmenler araciığıyla alışkanlıklar kazandırıması ile ilgili yapılan araştırmalar ışı̆̆ında, çalışmanın amacı, öğrencilere ağız diş sağlı̆ı farkındalığının kazandırılmasında, diş hekimi ile öğretmen eğitiminin etkinliğinin karşılaştırılması, eğitimde daha geniş kitlelere ulaşılabilmesinde en etkin yöntemin saptanmasıdır.

\section{GEREÇ VE YÖNTEM}

Çalışmada öğretmenin ve diş hekiminin verdiği eğitimin etkinliği karşılaştııımaktadır. İki farklı eğitimle artan bilgi seviyesinin fırçalama alışkanlığı, ağız hijyeni, plak indeks ve çürük indeksleri üzerindeki etkisi eğitim öncesi ve sonrası değerlendirilerek incelenmektedir. Çalışma öncesi İl Sağlık Müdürlüğü, İl Milli Eğitim Müdürlüğü, İlçe Milli Eğitim Müdürlüğüyle okul müdürlüğünden ve öğrenci velilerinden ağız diş sağlı̆ı eğitimi ve ağız muayeneleri için gerekli izinler alınmıştır. Çalışmada sosyoekonomik düzeyi düşük bölgedeki devlet okulunda okuyan, 83 kIz, 77 erkek toplam 160 kişiden oluşan, 6-7 yaşındaki birinci sınıf öğrencileri A ve B grubu olarak ayrılmıştır. Çalışmada A grubuna 80, B grubuna 80 çocuk dahil edilmiştir. Çalışma grupları arasında $\mathrm{d}=0.25$ etki büyüklüğünü ve $\% 80$ güç oranını, \%95 güven aralı̆ında hesaplayabilmek için, örneklem büyüklüğü, gereç ve yöntemi bizim çalışmamızla benzer olan Chandrashekar ve ark. ${ }^{13}$ göz önünde bulundurularak belirlenmiştir. ${ }^{4}$ Çalışmamızın etki büyüklüğü $d=0.27$, gücü ise $\% 84$ olarak hesaplanmışıı. Çalışmamızda A grubundaki öğrencilere eğitim verilmeden sadece öğretmen bilgilendirilmiştir. B grubundaki öğrenciler kontrol grubu olarak alınmıştır ve diş hekimi tarafından eğitim verilmiştir. A grubundaki çocukların öğretmen- lerine uygulamalı olarak bilgi verilmiştir ve öğretmen aynı gün kendi grubuna eğitim vermiştir. Bir haftalık süre içinde çocuklara hatıllatmalar yapması istenmiştir. Çalışma ilkokul birinci sınıf çocuklarında yürütüldüğünden eğitim resimli görsel materyaller ile yapılmıştır. Diş fırçalama eğitimi model üzerinde uygulamalı olarak gösterilmiş̧ir. Yazılı ifadeler kullanılmamıştır. Çocuklara verilen ağız diş sağlığı eğitimlerinde dişlerin sayısı, önemi, sağlıkı besinler, diş fırçalama sıklığı ve şekli, diş macunu kullanımı ve miktarı anlatılmıştır. Yapılan eğitim resimlerle ve sözlü olarak gerçekleştirilmiştir. ${ }^{14-}$ ${ }^{16}$ Çocukların sıkılmadan dikkatlerini toplayabilmeleri için eğitim 20 dakika süre ile sınırlı tutulmuştur. Eğitimi veren hekim ile muayeneleri gerçekleştiren hekim farklı olup eğitim öncesi ve sonrası muayeneleri aynı hekim gerçekleştirmiştir. Muayeneleri gerçekleştiren hekime gruplar hakkında bilgi verilmemiştir. Çocukların diş fırçalama sıkığı, plak indeksi, ağız hijyeni ile def-t (çürük çekilmiş dolgulu süt dişi), def-s (çürük çekilmiş dolgulu süt dişi yüzeyi), DMF-T (çürük çekilmiş dolgulu daimi diş) ve DMF-S (çürük çekilmiş dolgulu daimi diş 
yüzeyi) indeks değerleri incelenmiştir. Diş fırçalama sıklı̆ı hiç fırçalamayan, düzensiz firçalayan, günde bir kez firçalayan ve günde iki üç kez firçalayan olmak üzere dört farklı şekilde değerlendirilmiştir. Ağız hijyeni ise iyi, orta ve kötü olarak ayrımıştır. Plak indeksi, Sillness \& Loe plak indeksi kullanılarak Şekil 1 'de gösterilen dişlerle değerlendirmeye alınmıştır. ${ }^{17}$

Plak indeksinde dişetiyle temasta olan plak değerlendirilmeye alınmıştır. İndeks değerleri $0,1,2,3$ şeklinde belirtilmiştir. Hem A grubundaki çocukların öğretmenlerine hem de B grubundaki çocuklara aynı çocuk diş hekimi eğitim verirken, ilk ve 3 ay sonraki bilgi düzeylerinin davranışa yansımasını ölçmek için yapılan çürük indeks testlerinin muayenesi, grupları bilmeyen başka bir diş hekimi tarafından gerçekleştirilmiştir.

\section{İstatistiksel Analizler}

Çalışmanın nümerik verileri için Normalite testi yapılmıștır. \%95 güven aralığında yapılan Shapiro-Wilk normalite testi sonucunda verilerin non-parametrik olduğu saptanmıştır. Gruplar arası karşılaştırmalar için Mann Whitney U testi uygulanırken, ölçüm dönemleri arası karşılaştırmalar için Wilcoxon testi uygulanmıştır. Nümerik olmayan verilerin analizi için Ki Kare testi yapılımışı̆.

\section{BULGULAR}

Çalışmada, 6-7 yaşında, 83 kız 77 erkek toplam 160 çocuk değerlendirilmiştir. Çalışmaya dahil edilen çocukların cinsiyet dağııımı gruplar arası benzer bulunmuştur $(p>0,05)$. Gruplar arası kız ve erkek çocuk dağılımları arasında da anlamlı bir fark bulunamamıştır $(p>0,05)$.

Başlangıç verileri ile eğitim sonrası plak indeksi, DMF-T, DMF-S, def-t, def-s verilerinde eğitim verenler arasında değerlendirildiğinde anlamlı bir fark bulunamamıştır ( $p>0,05)$. Eğitim öncesi ile sonrası verileri karşılaştırıldığında ise plak indeksi, DMF-T, DMF-S, def$t$, def-s verilerinde benzer olduğu görülmüştür ( $p>0,05)$ (Tablo 1).

Ağız hijyeni değerlendirmelerine bakıldığında, başlangıç ve eğitim sonrası verilerinde gruplar arasında ve iki grupta eğitim öncesi ve sonrası verileri arasında istatistiksel olarak anlamlı bir fark bulunamamıştır $(p>0,05)$. Ancak her iki grupta da eğitim sonrası ağız hijyenlerinde iyileşme görülmüştür. Özellikle öğretme- nin eğitim verdiği grupta iyi ağız hijyenine sahip bireylerin artışının daha fazla olduğu belirlenmiştir (Şekil 2).

Diş fırçalama sıklığına baktığımızda, gruplar arası başlangıçta ve eğitim sonrası anlamlı bir fark görülmezken, eğitim öncesi ve sonrası verilerinde de her iki grup benzer bulunmuştur ( $p>0,05)$ (Şekil 3).

Tablo 1. Çalışma Gruplarında Plak İndeksi, DMFT, DMFS, deft, defs değerleri.

\begin{tabular}{|l|l|l|l|}
\hline & & Öğretmen & Diş Hekimi \\
\hline $\begin{array}{l}\text { Plak } \\
\text { Indeksi }\end{array}$ & $\begin{array}{l}\text { Eğitim } \\
\text { öncesi }\end{array}$ & $2,00(2,00-1,37)$ & $2.00(2,00-1,33)$ \\
\cline { 2 - 4 } & $\begin{array}{l}\text { Eğitim } \\
\text { sonrası }\end{array}$ & $2,00(2,00-1,00)$ & $2,00(2,00-1,00)$ \\
\hline \multirow{2}{*}{ DMFT } & $\begin{array}{l}\text { Eğitim } \\
\text { öncesi }\end{array}$ & $0,00(0,00-0,00)$ & $0,00(0,75-0,00)$ \\
\cline { 2 - 4 } & $\begin{array}{l}\text { Eğitim } \\
\text { sonrası }\end{array}$ & $0,00(0,00-0,00)$ & $0,00(1,00-0,00)$ \\
\hline \multirow{2}{*}{ DMFS } & $\begin{array}{l}\text { Eğitim } \\
\text { öncesi }\end{array}$ & $0,00(0,00-0,00)$ & $0,00(0,75-0,00)$ \\
\cline { 2 - 4 } & $\begin{array}{l}\text { Eğitim } \\
\text { sonrası }\end{array}$ & $0,00(0,00-0,00)$ & $0,00(1,00-0,00)$ \\
\hline \multirow{2}{*}{ deft } & $\begin{array}{l}\text { Eğitim } \\
\text { oncesi }\end{array}$ & $4,00(6,00-1,00)$ & $2,50(5,75-0,00)$ \\
\cline { 2 - 4 } & $\begin{array}{l}\text { Eğitim } \\
\text { sonrası }\end{array}$ & $4,00(6,00-1,00)$ & $2,52(6,00-0,00)$ \\
\hline defs & $\begin{array}{l}\text { Eğitim } \\
\text { öncesi }\end{array}$ & $4,00(8,00-1,50)$ & $3,00(8,25-0,00)$ \\
\cline { 2 - 4 } & $\begin{array}{l}\text { Eğitim } \\
\text { sonrası }\end{array}$ & $4,00(8,00-1,50)$ & $3,00(8,75-0,00)$ \\
\hline
\end{tabular}

Veriler Medyan(Q3-Q1) olarak verilmiştir. Gruplar ve ölçüm zamanları arasında anlamlı bir fark bulunamamıştır ( $p>0,05)$, (Tablo 1$)$.

\begin{tabular}{ll|ll}
6 & 1 & IV \\
\hline IV & 1 & 6
\end{tabular}

Şekil 1. Plak İndeksi değerlendirilen dişlerin numaraları

Gruplar ve ölçüm zamanları arasında anlamlı bir fark bulunamamıştır ( $p>0,05)$, (Şekil 2). 


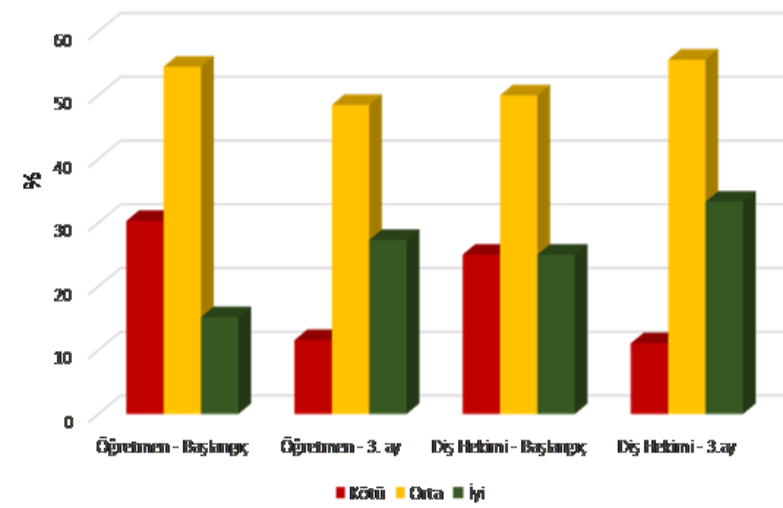

Şekil 2. Kötü, orta ve iyi olarak değerlendirilen ağız hijyeni verilerinin eğitim öncesi ve sonrası eğitim veren kişilere göre yüzdelik dağılımları

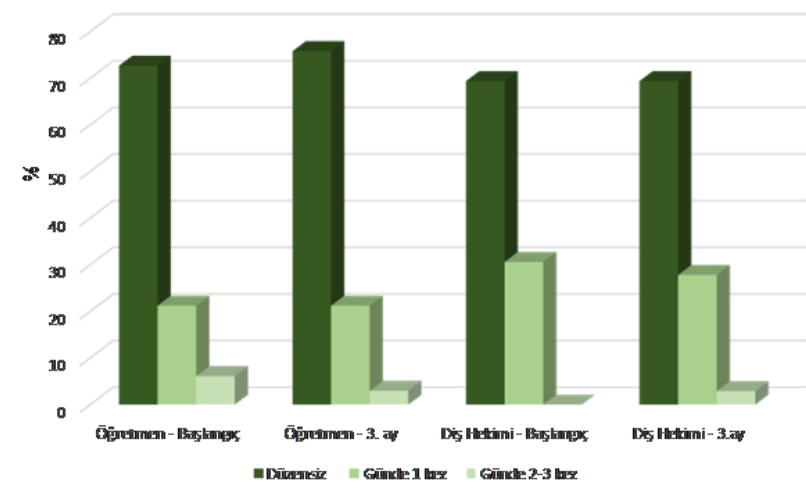

Şekil 3. Diş fırçalama sıklı̆ının eğitim öncesi ve sonrası eğitim veren kişilere göre yüzdelik dağılımları

Gruplar ve ölçüm zamanları arasında anlamlı bir fark bulunamamıştır ( $p>0,05)$, (Şekil 3).

\section{TARTIŞMA}

Yapılan çalışmalara göre diş hekimleri tarafından verilen ağız diş sağlığı eğitimleri bilgi düzeyinde etkili olmaktadır, bununla birlikte davranışlara yansıması aynı ölçüde olmamaktadır. ${ }^{18-20}$ Ayrıca verilen bu eğitimler görsel, işitsel ve uygulamalı olsa da, ilkokul çağındaki çocuklarda adolesan çağdaki çocuklar kadar etkili olmamaktadır. ${ }^{21}$ Araştırmacılar bu durumu ilkokul çağındaki çocukların okula kıyasla ailelerinden daha çok etkilenmelerine bağlamaktadır. ${ }^{22,23}$ Bu bilgilerin ışığında, yapılan çalışmada öğretmen eğitiminin etkinliğinin okula yeni başlayan çocuklarda değerlendirmenin daha doğru olduğu düşünülmüştür. Ağız diş sağlığı eğitimlerinin davranışlara yansımasında tekrarlanarak verilmesi önemlidir. ${ }^{14-16}$ Çocuklara verilen eğitimin görsel, renkli ve ilgi çekecek şekilde olmasına dikkat edilmelidir. Ayrıca kısa ve net ifadeler kullanılmalıdır. ${ }^{14-16}$ Diş hekiminin okul ortamında vereceği eğitim hem süre hem de sıklık açısından öğretmene kıyasla çok kısıtlı olmakta ve öğretmenler dolaylı olarak çocukların motivasyonunda daha etkili olmaktadır.,24 Yapılan çalışmada öğretmenlerin diş hekimlerine kıyasla ağız sağlığı eğitimindeki etkinlikleri tespit edilmeye çalışılarak en etkili öğrenme ve davranış geliştirme şeklinin belirlenmesinde yararlı olunması amaçlanmıştır. Ağız sağlığı eğitiminde öğretmenlerin etkinliklerinin değerlendirildiği bir çalışmada, 6-12 yaş okul çocuklarının bilgi seviyesi ve ağız hijyeni gelişiminde istatistiksel olarak anlamlı bir artış, plak sevilerinde bir azalma gözlendiği, bununla birlikte bu gelişmenin okula yeni başlayan küçük yaş grubunda çok daha az olduğu bildirilmiştir. ${ }^{25}$ Yapılan çalışmada eğitim sonrası kontrol grubunda ağız hijyeninde istatistiksel olarak anlamlı olmayan bir düzelme gözlenirken, plak seviyesi benzer olarak bulunmuştur. Öğretmenlerin eğitim verdiği çocuklarda da benzer sonuçlar elde edilmesi, eğitimin görsel, işitsel ve uygulamalı olması ve tekrarlanarak yapılması durumunda dahi küçük yaş grubunda yeterli olmadığını düşündürmektedir. Hem diş hekimi hem de öğretmen eğitiminde aynı sonucun bulunması, aile faktörünün küçük yaş grubunda daha etkili olduğunu akla getirmektedir. ${ }^{26}$

Ağız sağlığı eğitim çalışmalarının ardından kısa süre sonra yapılan kontrol muayeneleri ve testlerde bilgi düzeyi, ağız hijyeni ve plak seviyesi kriter olarak alınmakta, def-t, def-s, DMF-T ve DMF-S indeks değerleri belirleyici olmadığından dahil edilmemektedir. Naidu ve ark., eğitimden 6 ay sonra df-t ve DMF-T indeks değerlerinde düşme saptadıklarını ifade etmişlerdir. ${ }^{25}$ Yapılan çalışmada 3 ay sonra def-t, def-s, DMF-T ve DMF-S indeks değerlerinde istatistiksel olarak anlamlı bir fark gözlenmemiştir.

Çalışmaların çoğunda eğitim sonrası 3-6 aylık kısa takip sürelerinde ağız hijyeninde iyi yönde gelişme olduğu bildirilmiştir. ${ }^{4,27-30}$ Öğretmenlere ağız sağlığı eğitimi vererek 8-10 yaş arası okul çocuklarına bu eğitimin aktarılmasını sağladıkları çalışmada, 6 ay sonra çocukların ağız hijyeninin düzeldiği bildirilmişdir. ${ }^{31}$ Yapılan çalışmada da ağız hijyeninin eğitim sonrası her iki grupta daha iyi yönde geliştiği gözlenmiştir. Öğretmenin eğitim verdiği grupta ağız hijyeni düzelen çocuk sayısının daha fazla olması öğretmenler aracılığıyla

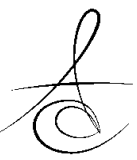


daha geniş kitlelere ulaşılabilmesi nedeniyle ümit verici olmuştur. Hebbal ve ark., 12 yaş çocuklarına verdikleri eğitim sonrası yaptıkları incelemelerde, ağız hijyeninde gelişme ve plak seviyesinde azalma olduğu bildirilmişdir. ${ }^{32}$ Chandrashekar ve ark., ortaokula giden 116 çocukta diş hekimi ile öğretmenin ağız sağlığı eğitimini karşılaştırmış, eğitim sonrası ağız hijyeninde iyileşme ve plak seviyesinde düşme tespit etmişlerdir. ${ }^{4}$ Ağız hijyeni düzelmesi açısından öğretmen eğitiminde diş hekimi eğitimine göre daha yüksek bir artış gözlenmiştir. Yapılan çalışmada da ağız hijyeni açısından benzer sonuçlar bulunmuştur. Hem Hebbal ve ark., hem de Chandrashekar ve ark., ${ }^{4,32}$ çalışmalarını ortaokul düzeyindeki çocuklarda yaptıklarından daha iyi yönde artış gözlemişlerdir. Bu değerler eğitimin etkinliğinin adolesan yaşlarda küçük yaş grubuna kıyasla daha fazla olduğu fikrini desteklemektedir. ${ }^{25,33}$

\section{SONUÇ}

Yapılan çalışmada aile faktörünü dahil etmeden küçük yaş grubu çocuklarda etkili ağız sağlığı eğitimiyle geniş kitlelere hızlı ve kolay ulaşılması hedeflenmiştir. Diş hekimi ile öğretmen eğitiminin etkinliği arasında fark gözlenememesi nedeniyle, ağız sağlığı eğitiminde daha geniş kitlelere daha sıklıkla ulaşabilmeleri bakımından öğretmenlerin daha etkin olacağı sonucuna varılmıştır. Öğretmen ve ailelerin birlikte çalışmaya dahil olduğu farklı aralıklarla yapılacak yeni çalışmaların planlanmasının ağız sağlığı eğitiminde faydalı olacağı düşünülmektedir.

Berna Kuter: ORCID ID: 0000-0002-1234-8237

Burcu Kanmaz: ORCID ID: 0000-0001-9100-8398

\section{KAYNAKLAR}

1. American Dental Association Health Foundation: Prevention in the dental office: results of a preventive dentistry survey. JADA 1984;108: 809-17.

2. Driscoll W.S. What we know and don't know about dietary fluoride supplements the research basis. J Dent Child 1985;52:259-64.

3. Aktören $O$, Seymen $F$, Akıncı T. Toplumun çürük profilaksisi konusundaki bilgi düzeyleri ve yaklaşımları. İ.Ü. Diş Hek Fak Derg 1990; 24: 106-11.

4. Chandrashekar BR, Suma S, Kiran K, Manjunahth $\mathrm{BC}$. The use of school teachers to promote oral hjgiene in some secondary school students at Hyderabad, Andhra Pradesh, India: A short term prospective pilot study. J Family Community Med 2012; 19: 184-9.

5. Kay EJ, Baba SP. Designing dental health education materials for school teachers: Formative evaluation research. J Clin Pediatr Dent 1991; 15:195-8.

6. Emson HE. Health, disease and illness: Matters for definition. CMAJ 1987; 136: 181-3.

7. Yurdasal B, Bozkurt Aİ, Öz İ, Tanrıverdi S, Taş E, Nalbant M. Denizli ağız diş sağlığını geliştirme projesi: 3 yıllık sonuçları. Türkiye Halk Sağlığı Derg 2012;10:44-52.

8. Gökalp S, Doğan BG, Tekçiçek M, Berberoğlu A, Ünlüer Ş. Beş, on iki ve on beş yaş çocukların ağız diş sağlığı profili, Türkiye-2004. Hacettepe Diş Hek Fak Derg 2007; 31:3-10.

9. Biesbrock AR, Walters PA, Bartizek RD. Shortterm impact of a national dental education program on children's oral health and knowledge. J Clin Dent 2004; 15:93-7.

10. Tai B, Du M, Peng B, Fan M, Bian Z. Experience from a school-based oral health promotion programme in Wuhan City. PR China. Int J Paediatr Dent 2001;11:286-91.

11. Morishita M, Sakemi M, Tsutsumi M, Gake S. Effectiveness of an oral health promotion programs at workplace. J Oral Rehabil 2003; 30: 414-7.

12. Tezel A. Erzurum ili ilkokul 4. Ve 5. sınıf çocukların ağız ve diş sağlığı konusundaki bilgi tutum ve davranış düzeylerinin araştırılması. Yüksek Lisans Tezi, Atatürk Üniv Halk Sağlığı ABD, 1995.

13. Angelopoulou MV, Kavvadia K, Taoufik K, Oulis C]. Comparative clinical study testing the effectiveness of school based oral health education using experiential learning or traditional lecturing in 10 year-old children. BMC Oral Health 2015;15:51-8.

14. Eronat N, Koparal $E$, Ertuğrul F. Etkili bir ağız diş sağlığı eğitimi nasıl olmalı? Akademik Dental Diş Hek Derg 2000;2:38-45.

15. Emler BF, Windchy AM, Zaino SW, Feldman SM, Scheetz JP. The value of repetition and reinforcement in improving oral hygiene performance. J Periodontol 1980;51:228-34.

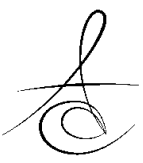


16. Harn SD, Dunning DG. Using a children is dental health carnival as a primary vehicle to educate children about oral health. ASDC J Dent Child 1996; 63:281-4.

17. Silness J, Loe $H$. Periodontal disease in pregnancy. II.Correlation between oral hygiene and periodontal condition. Acta Odontol Scand 1964; 22:121-35.

18. Kay $E$, Locker $D$. Is dental health education effective? A systematic review of current evidence. Community Dent Oral Epidemiol 1996;24:231-5.

19. Kay E, Locker D. A systematic review of the effectiveness of health promotion aimed at improving oral health. Community Dent Health 1998;15:132-44.

20. Farias IA, Souza GC, Ferreira MA. A health education program for Brazillian public school children in the effects of dental health practise and oral health awareness. J Public Health Dent 2009;69:325-30.

21. Angelopoulou MW, Oulis CJ, Kavvadia K. School based oral health education program using experimental learning or traditional lecturing in adolescent a clinical trial. Int Dent J 2014; 64: 278-84.

22. Lu M, Zhu I, Zhang B, Peterson PE. Changing use and knowledge on fluoride toothpaste by school children, parents and school teachers in Beijing China. Int Dent J 2007;57:187-94.

23. Okada M, Kawamura M, Kaihara Y, Matsuzaki Y, Kuwahara S, Ishidori $H$. Influences of parents oral health behaviour on oral health status of their school children an exploratory study employing a casual modelling technique. Int J Paediatr Dent 2002;12:101-8.

24. Boran Z, Eden E. 11-12 yaş çocuklarında ağız diş sağlığı eğitiminin etkinliğinin değerlendirilmesi. Ege Üniversitesi Diş Hek Fak Pedodonti Ana Bilim Dalı bitirme tezi. 2009

25. Naidu J, Nandlal B. Evaluation of the effectiveness of a primary preventive dental health education programme implemented through school teachers for primary school children in mysore city. J Int Soc Prev Community Dent 2017; 7:82-9.
26. Conrado CA, Maciel SM, Oliveira MR. A schoolbased oral health educational program: The experience of Maringa-Pr, Brazil. J Appl Oral Sci 2004;12:7-33.

27. Kapadia H, Stallard V, Butler M. Evaluation of a curriculum for dental health in 3rd grade school children in Mumbai, India. J Indian Soc Pedod Prev Dent 1999;17:65-8.

28. Thomas S, Tandon S, Nair S. Effect of dental health education on the oral health status of a normal child population by involving target groups. J Indian Soc Pedod Prev Dent 2000;18:115-25.

29. Walia T, Tewari A, Chawla HS, Goyal A. Effect of training school teachers on KAP and dental caries of 7-9 years old school children. J Indian Soc Pedod Prev Dent 2000;18:47-53.

30. Aljanakh M, Siddiqui AA, Mirza AJ. Teachers' knowledge about oral health and their interest in oral health education in Hail, Saudi Arabia. Int J Health Sci 2016;10:87-93.

31. Jain S, Bhat N, Asawa K, Tak M, Singh A, Shinde $K$, Gandhi N, Doshi A. Effect of training school of 8-10 years old goverment school children of Udaipur city, India. J of Clinical and Diagnostic Research 2016;10:95-9.

32. Hebbal M, Ankola AV, Vadavi D, Patel K. Evaluation of knowledge and plaque scores in school children before and after health education. Dent Res J (Isfahan) 2011;84:189-96.

33. Kemaloğlu H, Yıldırım K, Kaya A, Önal B. İzmir ilinin Seferihisar ilçesindeki 8-12 ve 13-16 yaş aralığındaki çocuklarda çürük dağııııının değerlendirilmesi, Bölüm:1. Atatürk Üniv Diş Hek Fak Derg 2014; 24: 353-9.

\section{Yazışma Adresi}

Dr.Öğr.Üyesi Berna KUTER

İzmir Demokrasi Üniversitesi

Pedodonti Anabilim Dalı, İzmir/Türkiye

TEL:+90 2322601001

FAX:+90 2322601004

e-mail:berna.kuter@idu.edu.tr 